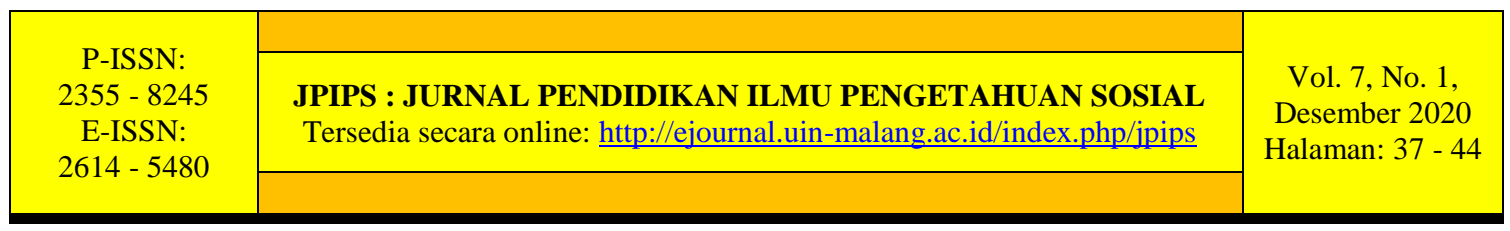

\title{
RANCANGAN ATRAKSI WISATA EDUKASI DI KAMPUNG HIJAU KOTA BANJARMASIN
}

\author{
Selamat Riadi ${ }^{*}$, Ellyn Normelani' ${ }^{2}$ Ahmad Alim Bachri ${ }^{3}$ \\ Nur Hidayah $^{4}$, Yulika Puspita Sari ${ }^{5}$ \\ 1,2,3,4,5 Universitas Lambung Mangkurat \\ *1 selamatriadi@ulm.ac.id
}

Diterima: 22-09-2020.; Direvisi: 16-12-2020; Disetujui: 22-12-2020

Permalink/DOI: 10.1886/jpips.v7i1.10364

Abstrak: Kota Banjarmasin merupakan daerah tujuan wisata yang cukup populer dengan obyek wisata sungainya. Salah satu destinasi wisata di Kota Banjarmasin yang menawarkan nuansa khas budaya banjar yang berbasis sungai adalah Kampung Hijau. Kampung Hijau merupakan obyek wisata di tepian sungai yang dikembangkan dengan pendekatan Community-based Tourism (CBT). Tujuan dari penelitian ini adalah untuk merancang atraksi wisata edukasi di destinasi wisata Kampung Hijau Kota Banjarmasin. Penelitian ini menggunakan pendekatan kualitatif dengan jenis deskiptif. Pengumpulan data melalui, wawancara, observasi dan studi dokumentasi. Rancangan atraksi wisata edukasi di Kampung Hijau Kota Banjarmasin adalah memberikan pengetahuan dasar mengenai tindakan adaptasi dan mitigasi masyarakat terhadap perubahan iklim dan berbagai hal lain yang terdapat di destinasi wisata, serta meningkatkan pengetahuan dan pemahaman wisatawan dengan melihat secara langsung kegiatan adaptasi dan mitigasi yang dilakukan oleh masyarakat.

\section{Kata Kunci: Atraksi; Wisata edukasi; Kampung hijau}

Abstract: Banjarmasin city is a popular tourist destination for its river tourism. One of the tourist destinations that offer a distinctive atmosphere of river-based Banjar culture is Kampung Hijau. This tourist attraction is located on the Martapura river banks, which was developed with a Community-based Tourism (CBT) approach. This study aims to design educational tourist attractions in the Kampung Hijau tourist destination. This study uses a qualitative approach with descriptive types. Data collection was carried out by the survey, interview, and documentation study. The design of educational tourism attractions designed in Kampung Hijau provides basic knowledge of community adaptation and mitigation actions against climate change and other matters. It increases tourist knowledge and understanding by firsthand the community's adaptation and mitigation activities.

Keywords: Attraction; Education tourism; Kampung hijau 


\section{PENDAHULUAN}

Kota Banjarmasin merupakan salah satu Kota di Indonesia yang berada di wilayah Provinsi Kalimantan Selatan. Secara geografis Kota Banjarmasin berada pada posisi dan peranan yang sangat penting di Kalimantan Selatan. Menurut Rencana Pembangunan Jangka Panjang (RPJP) Kota Banjarmasin Tahun 2006-2025 disebutkan bahwa Kota Banjarmasin merupakan pusat Pemerintahan Provinsi Kalimantan Selatan, kota industri, kota pelabuhan, kota perdagangan, kota pariwisata dan pusat informasi.

Berkaitan dengan pariwisata Kota Banjarmasin tergolong sangat potensial untuk dikembangkan lebih maju lagi. Kota Banjarmasin memiliki potensi pariwisata yang cukup besar dan beragam khususnya daya tarik wisata sungai. Menurut Peraturan Daerah Kota Banjarmasin Nomor 28 Tahun 2012 tentang Kepariwisataan disebutkan bahwa "Kota Banjarmasin tidak dapat mengandalkan Pendapatan Asli Daerah (PAD) dari hasil sumber daya alam yang tidak dipunyai, oleh karenanya pengembangan industri pariwisata menjadi alasan utama sebagai salah satu upaya meningkatkan PAD melalui pemanfaatan potensi-potensi yang dimiliki”.

Salah satu jenis industri yang dapat dimanfaatkan daerah untuk meningkatkan PAD adalah obyek wisata. Pemerintah Kota Banjarmasin saat ini terus meningkatkan perkembangan pariwisata, yakni melalui beberapa program yang telah direncanakan maupun yang telah dilaksanakan seperti kampanye sadar wisata, menambah dan membangun destinasi tujuan wisata, festival budaya, dan lain sebagainya. Tentunya hal tersebut dilakukan agar meningkatnya jumlah wisatawan yang datang dan semakin lama melakukan wisata.

Obyek wisata yang terdapat di Kota Banjarmasin jenisnya bervariasi. Secara rinci obyek wisata di Kota Banjarmasin berdasarkan jenisnya dapat dilihat pada Tabel 1 berikut.

Tabel 1. Obyek Wisata di Kota Banjarmasin

\begin{tabular}{ll}
\hline \multicolumn{1}{c}{ Nama Obyek Wisata } & Jenis Obyek Wisata \\
\hline Pasar Terapung Kuin & Wisata Budaya \\
Pasar Terapung Siring Tendean & Wisata Buatan \\
Taman Maskot Bekantan & Wisata Buatan \\
Menara Pandang & Wisata Buatan \\
Rumah Anno 1925 & Wisata Budaya \\
Kampung Rumah Banjar & Wisata Budaya \\
Muesum Wasaka & Wisata Buatan \\
Kampung Sasirangan & Wisata Buatan \\
Masjid Sultan Suriansyah & Wisata Religi \\
Makam Sultan Suriansyah & Wisata Religi \\
Klenteng dan Pecinan & Wisata Religi \\
Kampung Hijau & Wisata Buatan \\
\hline Sumber: Data Sekunder diolah &
\end{tabular}

Sumber: Data Sekunder, diolah (2020)

Obyek wisata di Kota Banjarmasin yang banyak dikunjungi wisatawan pada tahun 2019 berdasarkan informasi dari Dinas Dinas Kebudayaan dan Pariwisata Banjarmasin yaitu: Pasar Terapung Siring Tendean, Mesjid dan Makan Sultan Suriansyah, Pasar Terapung Kuin, Menara Pandang, Taman Maskot Bekantan, Kampung Sasirangan.Obyek wisata yang dikelola dengan baik terbukti mampu 
memberikan kontribusi bagi pembangunan daerah. Dampak posistif dari pengembangan pariwisata bagi masyarakat adalah menambah lapangan pekerjaan, meningkatkan pendapatan daerah melalui retribusi, pajak dan lain sebagainya. Selain dampak positif dari segi ekonomi, dikembangkannya suatu obyek wisata dengan dibangunnya fasilitas dan infrastruktur secara tidak langsung juga telah melakukan pemerataan pembangunan.

Kampung Hijau sebagai salah satu destinasi wisata baru di Kota Banjarmasin, yang dikembangkan dengan pendekatan Community-based Tourism (CBT) menawarkan daya tarik wisata dengan nuansa khas budaya banjar yang berbasis sungai. Communitybased Tourism (CBT) merupakan suatu pendekatan pembangunan pariwisata yang melibatkan masyakarat lokal sebagai pengambil keputusan dan penerima manfaat. Community-based Tourism (CBT) dikembangkan berdasarkan prinsip keseimbangan dan keselarasan antara kepentingan pemerintah, swasta (Tisnawati \& Ratriningsih, 2017; Nasruddin et al., 2019). Ciri khas masyarakat Kampung Hijau yang berada di Sungai Bilu Kota Banjarmasin adalah setiap rumah berwarna hijau, hingga pagar dan atap bangunan. Kampung Hijau tepat berada di bantaran Sungai Martapura sepanjang 800 meter, yang dulunya merupakan pemukiman kumuh.

Salah satu upaya dalam pengembangan obyek wisata yang melibatkan masyarakat adalah dengan melakukan rancangan wisata edukasi. Wisata edukasi merupakan perjalanan wisata yang dimaksudkan untuk memberikan gambaran, pengetahuan atau pengalaman belajar secara langsung kepada wisatawan tentang lokasi wisata yang dikunjungi. Motivasi seseorang melakukan perjalanan wisata adalah untuk berlibur, rekreasi, kesehatan, minat atas budaya, kesenian, pendidikan dan penelitian (Suwantoro, 1997).

Wisata edukasi menjadi salah satu alternatif pengembangan obyek wisata yang diharapkan dapat memperkuat kearifan lokal budaya lokal yang ada. Selain itu juga sebagai salah satu upaya dalam mengatasi faktor penghambat mewujudkan misi Kota Banjarmasin 2016-2021 dalam pengelolaan wisata sesuai Revisi Renstra Dinas Kebudayaan dan Pariwisata Kota Banjarmasin Tahun 2016-2021 diantara yaitu: 1) potensi sungai belum terkelola dengan baik; 2) kurangnya kesadaran masyarakat untuk menjaga dan melestarikan sungai; dan 3) tingkat apresiasi masyarakat terhadap budaya tradisional yang masih kurang.

Selain masalah kepariwisataan yang menjadi faktor penghambat dalam pengelolaan wisata tersebut rancangan wisata edukasi ini sejalan dengan arah pengembangan wisata Kampung Hijau yakni upaya pemerintah Kota Banjarmasin merubah kebiasaan acuh masyarakat menjadi peduli akan lingkungan khususnya sungai. Berdasarkan lata belakang tersebut, maka tujuan penelitian ini adalah untuk merancang atraksi wisata edukasi di destinasi wisata Kampung Hijau Kota Banjarmasin.

\section{METODE}

Penelitian ini dilakukan di obyek wisata Kampung Hijau pada Agustus 2020 tepatnya di Kelurahan Sungai Bilu, Kecamatan Banjarmasin Timur, Kota Banjarmasin. Sumber data dalam penelitian ini terdiri dari data perimer dan data sekunder. Data 
primer berupa informasi tentang obyek wisata Kampung Hijau dengan narasumber yaitu warga sekitar obyek wisata. Data sekunder berupa berbagai dokumen yang relevan dari berbagai sumber. Pengumpulan data dilakukan dengan wawancara, observasi, dan metode dokumentasi. Data dianalisis secara deskriptif kualitatif, dengan rangkaian kegiatan yaitu reduksi data, penyajian data, penafsiran data, dan menarik kesimpulan (Miles \& Huberman, 1992).

\section{HASIL DAN PEMBAHASAN \\ Hasil}

Hasil penelitian menunjukkan bahwa obyek wisata Kampung Hijau di Kota Banjarmasin berpotensi untuk dikembangkan sebagai wisata edukasi. Hal tersebut didasarkan pada jumlah siswa atau pelajar di Kalimantan Selatan yang cukup besar sebagai segmentasi pasar utama wisata berbasis edukasi. Secara rinci jumlah siswa atau pelajar di Kalimantan Selatan berdasarkan jenjang pendidikannya dapat dilihat pada Tabel 2 berikut.

Tabel 2. Jumlah Siswa/Pelajar Berdasarkan Jenjang Pendidikan di Provinsi Kalimantan Selatan Tahun 2019/2020

\begin{tabular}{|c|c|c|c|c|c|}
\hline \multirow[b]{2}{*}{ Kabupaten/Kota } & \multicolumn{4}{|c|}{ Siswa/Pelajar } & \multirow[b]{2}{*}{ Jumlah } \\
\hline & TK/RA & SD/MI & MP/MTs & $\begin{array}{c}\text { SMA/ } \\
\text { SMK/MA }\end{array}$ & \\
\hline Tanah Laut & 10.913 & 40.563 & 13.804 & 12.576 & 77.856 \\
\hline Kotabaru & 9.430 & 39.367 & 15.390 & 11.801 & 75.988 \\
\hline Banjar & 10.029 & 58.760 & 22.915 & 17.977 & 109.681 \\
\hline Barito Kuala & 7.742 & 34.869 & 14.406 & 11.196 & 68.213 \\
\hline Tapin & 5.857 & 21.086 & 7.575 & 6.551 & 41.069 \\
\hline Hulu Sungai Selatan & 6.509 & 24.519 & 9.133 & 7.722 & 47.883 \\
\hline Hulu Sungai Tengah & 7.763 & 26.912 & 11.785 & 10.921 & 57.381 \\
\hline Hulu Sungai Utara & 7.305 & 24.840 & 10.536 & 9.862 & 52.543 \\
\hline Tabalong & 9.208 & 30.122 & 11.901 & 11.681 & 62.912 \\
\hline Tanah Bumbu & 11.838 & 40.644 & 15.685 & 14.034 & 82.201 \\
\hline Balangan & 5.378 & 15.103 & 5.769 & 5.351 & 31.601 \\
\hline Banjarmasin & 18.151 & 71.141 & 29.924 & 30.937 & 150.153 \\
\hline Banjarbaru & 8.832 & 29.415 & 13.436 & 13.234 & 64.917 \\
\hline Kalimantan Selatan & 118.955 & 457.341 & $\mathbf{1 8 2 . 2 5 9}$ & $\mathbf{1 6 3 . 8 4 3}$ & 922.398 \\
\hline
\end{tabular}

Sumber: Data Sekunder, diolah (2020).

Tabel 2 di atas menunjukkan bahwa siswa atau pelajar di Kalimantan Selatan memiliki jumlah yang cukup besar yakni sebanyak 922.398. Jika dilihat dari jenjang pendidikannya didominasi oleh siswa atau pelajar jenjang SD yakni sebanyak 381.891 dan diikuti jenjang SMP yakni sebanyak 115.179. Sedangkan jika dilihat wilayahnya didominasi oleh Kota Banjarmasin yakni sebanyak 150.153 siswa atau pelajar. Hal tersebut menunjukkan bahwa obyek wisata Kampung Hijau berpotensi untuk diekmbangkan menjadi wisata edukasi.

Berdasarkan hasil observasi yang telah dilakukan di obyek wisata Kampung Hijau Kota Banjarmasin, menunjukkan bahwa masyarakat di obyek wisata memiliki tanggung jawab yang besar dalam upaya perlindungan dan pengelolaan lingkungan. Masyarakat mendukung pembangunan kawasan obyek wisata melalui tata kelola kampung. Masyarakat di obyek wisata kampung hijau memiliki kesadaran yang tinggi dalam hal pelestarian lingkungan melalui partisipasi yang aktif dalam Program Kampung Iklim (PROKLIM) dari Pemerintah Kota Banjarmasin. 
Berdasarkan hasil wawancara dengan beberapa warga yang bertempat tinggal di obyek wisata Kampung Hijau, mereka memberikan respon yang positif terhadap keberadaan obyek wisata ini. Masyarakat menyatakan keberadaan obyek wisata Kampung Hijau meningkatkan perekonomian mereka, selain itu masyarakat sekitar juga memperoleh ilmu pengetahuan dalam adaptasi dan mitigasi terhadap perubahan iklim melalui PROKLIM. Sampai saat penelitian ini dilakukan, sepanjang 800 meter dibantaran sungai martapura yang dikembangkan pemerintah sebagai obyek wisata Kampung Hijau, masyarakat memanfaatkan pekarangan rumah untuk budidaya berbagai tanaman dan peternakan untuk konsumsi sendiri dan dijual seperti tanaman lombok, tomat, tanaman hias, budidaya ikan nila, ikan patin, dan ternak ayam. Selain itu masyarakat juga menerapkan pola 3M (menutup, menguras, menimbun), dan memiliki kewaspadaan yang tinggi terhadap penyakit yang diakbitkan oleh perubahan iklim seperti diare, malaria dan DBD.

Kampung Hijau ini selain menjadi obyek wisata susur sungai dengan ciri khas setiap rumah berwarna hijau, hingga pagar dan atap bangunan juga merupakan tempat wisata edukasi. Wisatawan sangat diperbolehkan sekali untuk melakukan wisata edukasi disana, tanpa dipungut biaya. Wisata edukasi yang dapat dilakukan wisatawan yaitu memperoleh ilmu dalam adaptasi dan mitigasi terhadap perubahan iklim, selain itu juga dalam pembuatan kerupuk udang dan ikan haruan (gabus).

\section{Pembahasan}

Pengembangan suatu obyek wisata baik skala kecil maupun skala besar tentunya harus dilengkapi dengan strategi perencanaan yang baik. Pentingnya suatu perencanaan dalam pengembangan obyek wisata adalah agar apa yang telah dirumuskan mencapai hasil yang dikehendaki baik ditinjau dari segi ekonomi, sosial, budaya dan lingkungan. Perencanaan dapat memberikan suatu informasi tentang bagaimana langkah-langkah yang akan diambil sesuai dengan kondisi kawasan yang dikelola (Fandeli, 2002) .

Berdasarkan hasil penelitian terkait dengan rancangan atraksi wisata edukasi di Kampung Hijau sangat berpotensi untuk dikembangkan, hal tersebut didasarkan pada jumlah siswa atau pelajar di Kalimantan Selatan yang sangat besar. Siswa atau pelajar merupakan segmentasi pasar utama dalam pengembangan wisata edukasi (Priyanto et al., 2018). Artinya dengan potensi wisatawan yang banyak, maka Kampung Hijau semakin potensial untuk dikembangkan menjadi wisata edukasi.

Rancangan atraksi wisata edukasi dalam penelitian ini didasarkan pada temuan beberapa potensi yang ada di obyek wisata Kampung Hijau. Atraksi wisata merupakan motivasi bagi wisatawan dalam melakukan kunjungan ke obyek wisata. Atraksi wisata dapat dikatakan modal utama dalam pengembangan pariwisata (Suwena \& Widyatmaja, 2017; Fitroh et al., 2017).

Atraksi wisata edukasi Kampung Hijau yang dirancang dalam penelitian ini menekankan pada pembelajaran kepada anak TK, SD, SMP, hingga SMA. Wisata edukasi merupakan program wisata yang dirancang dengan tujuan utama memberikan pengalaman belajar langsung terkait dengan kawasan wisata yang dikunjungi (Harris et al., 2014; Ridhoi et al., 2020). Atraksi wisata edukasi yang dirancang bertujuan untk memberikan pendidikan dan pembelajaran kepada wisatawan (Yfantidou \& Goulimaris, 2018; Dembovska et al., 2016; Hasdian \& Setiyorini, 2017). Daya tarik wisata Kampung Hijau adalah kegiatan mitigasi dan adaptasi masyarakat terhadap perubahan iklim dengan berbagai kegiatan yang dapat dijadikan atraksi wisata edukasi. 
Keterlibatan masyarakat dan dukungan pemerintah yang tinggi menjadikan suatu obyek wisata potensial untuk dikembangkan (Palimbunga, 2018). Pengembangan menjadi wisata edukasi dengan rancangan atraksi kegiatan yang telah dilakukan oleh masyarakat kawasan obyek wisata. Hasil temuan masyarakat memiliki keterlibatan dalam pengembangan obyek wisata Kampung Hijau, terutama dalam rangka menjaga lingkungan. Hal ini didukung oleh temuan Normelani et al., (2020), menunjukkan bahwa persepsi masyarakat terhadap adaptasi dan mitigasi perubahan iklim berada pada kategori baik.

Atraksi wisata edukasi yang dirancang pada obyek wisata Kampung Hijau adalah wisatawan yang berkunjung diperkenalkan cara masyarakat menjaga lingkungan dan diajak ikut melakukan usaha adaptasi dengan langkah-langkah sebagai berikut:

1. Atraksi wisata edukasi penyuluhan tentang pola hidup bersih dan sehat: wisatawan diberi informasi bagaimana cara hidup bersih dan sehat dengan diajak keliling kampung hijau, memberikan contoh langsung bagaimana sirkulasi udara yang baik pada sebuah rumah,memberikan contoh pengelolaan sampah, penanaman pohon dll.

2. Atraksi wisata edukasi pembuatan pupuk organic: masyarakat memberikan edukasi tentang larangan membakar sampah,memberikan edukasi tentang kegiatan $3 \mathrm{R}$

(Reduce, Reuse, Recycle) wisatawan melakukan pemilahan sampai, kemudian sampah organik dibuat pupuk organis (kompos) melalui bimbingan masyarakat, dari cara pembuatannya sampai pengemasan.

3. Atraksi wisata edukasi pemanfaatan perkarangan untuk budidaya tumbuhan: wisatawan diberikan informasi tentang berbagai budidaya yang ditanam masyarkat mulai dari nama, manfaat serta khasiat tanaman tersebut, wisatawan diajak menanam berbagai bibit tanaman tersebut pada polybag yang telah disediakan dengan mengunakan pupuk organic yang telah mereka coba buat sendiri, nantinya polybag yang berisi bibit tanaman tersebut bisa mereka bawa pulang sebagai cenramata.

4. Atraksi wisata edukasi memanen budidaya tumbuhan diperkarangan warga seperti terong, ubi, pisang dll, wisatawan diajak memanen langsung hasil budidaya perkarangan.

5. Atraksi wisata edukasi olahan kuliner hasil dari perkarangan rumah warga: wisatawan mencoba membuat dan menikmati berbagai hasil olahan kuliner berbahan dasar yang dipanen dari perkarangan warga, masyarakat memberikan informasi alat dan bahan yang digunakan serta bagaimana cara membuatnya.

Perancangan atraksi wisata edukasi di Kampung Hijau diharapkan dapat meningkat jumlah kunjungan wisatawan, sehingga wisata menjadi salah satu sumber pemasukan masyarakat Kawasan wisata. Hal tersebut didukung oleh hasil temuan Anis \& Kaffah, (2020) bahwa perancangan atrakasi wisata berpengaruh terhadap kunjungan wisata. Perancangan atrakasi wisata edukasi ini didasarkan pada konsep pariwisata yang berkelanjutan. Konsep pariwisata berkelanjutan, yakni: 1) memeberi manfaat ekonomi kepada masyarakat setempat, 2) tidak merusak lingkungan, 3) bertanggung jawab secara social, 4) tidak bertentangan dengan budaya setempat (Hermawan et al., 2018).

Sasaran paket atraksi wisata edukasi yang dircancang dalam penelitian ini selain siswa atau pelajar juga mahasiswa dan masyarakat umum yang datang perorangan, rombongan kecil sampai dengan rombongan besar. Selain menikmati kampung hijau kerena semua rumah dicat hijau menjadi pemandangan unik tersendiri, wisatawan mendapat pengalaman mencoba melakukan adaptasi terhadap perubahan iklim secara 
langsung.

\section{KESIMPULAN}

Konsep wisata edukasi dalam penelitian ini adalah pengelolaan obyek wisata yang memadukan antara kegiatan berwisata dengan kegiatan edukasi. Atraksi wisata edukasi yang dirancang bertujuan agar wisatawan mendapatkan pembelajaran secara langsung di obyek wisata, dalam hal ini memahami budaya masyarakat banjar (budaya sungai), diperkenalkan bagaimana cara masyarakat bantaran sungai dalam menjaga lingkungan serta wisatawan diajak ikut melakukan usaha adaptasi terhadap perubahan iklim.

\section{UCAPAN TERIMA KASIH}

Terimakasih kami ucapkan kepada Universitas Lambung Mangkurat (ULM) yang tekah membiayai penelitian ini melalui dana PNBP Universitas tahun 2020 melalui kontak No. 212.237/UN8.2/PL/2020. Terimakasih pula kami ucapkan kepada LPPM ULM yang mendukung terselesaikannya kegiatan ini. Terimakasih pula kepada mahasiswa yang membantu penelitian ini.

\section{DAFTAR PUSTAKA}

Anis, M., \& Kaffah, S. (2020). Rancangan Pengembangan Wisata Budaya Kampoeng Batik Laweyan. Prosiding IENACO 2020, 379-384. https://publikasiilmiah.ums.ac.id/xmlui/handle/11617/11973

Dembovska, I., Silicka, I., \& L,ubkina, V. (2016). Educational Tourism in the Training of Future Tourism Professionals. SOCIETY. INTEGRATION. EDUCATION. Proceedings of the International Scientific Conference, 4, 245. https://doi.org/10.17770/sie2016vol4.1561

Fandeli, C. (2002). Perencanaan Kepariwisataan Alam. Fakultas Kehutanan Universitas Gadjah Mada.

Fitroh, S. K. A., Hamid, D., \& Hakim, L. (2017). Pengaruh Atraksi Wisata dan Motivasi Wisatawan terhadap Keputusan Berkunjung (Survei pada Pengunjung Wisata Alam Kawah Ijen). Jurnal Administrasi Bisnis (JAB), 42(2), 18-25. http://administrasibisnis.studentjournal.ub.ac.id/index.php/jab/article/view/1681

Harris, S., Ernawati, A., \& Laksmitasari, R. (2014). Revitalisasi Taman Wisata Sangraja Menjadi Pusat Wisata Edukasi dan Kebudayaan di Majalengka. Rosiding Temu Ilmiah IPLBI, 1-6.

Hasdian, A., \& Setiyorini, H. P. D. (2017). Pengaruh Educational Tourism Experience Terhadap Kepuasan Wisatawan Di Kampung Batu Malakasari. THE Journal: Tourism and Hospitality Essentials Journal, 6(2), 1085. https://doi.org/10.17509/thej.v6i2.5519

Hermawan, H., Brahmanto, E., \& Musafa, S. (2018). Upaya Mewujudkan Wisata Edukasi di Kampung Tulip Bandung. JURNAL ABDIMAS BSI: Jurnal Pengabdian Kepada Masyarakat, 1(1), 45-54. https://doi.org/10.31227/osf.io/8j3ym

Miles, B. M., \& Huberman, M. (1992). Analisis Data Kualitatif Buku Sumber Tentang Metode-metode Baru. UPI.

Nasruddin, N., Normelani, E., \& Kumalawati, R. (2019). Strategy for the Development of Kampung Sasirangan as Edutourism Village. Journal of Indonesian Tourism and Development $\quad$ Studies, $205-210$. 
https://doi.org/10.21776/ub.jitode.2019.007.03.10

Normelani, E., Kumalawati, R., Kartika, N. Y., Nugroho, A. R., Riadi, S., \& Efendi, M. (2020). Program Kampung Iklim (Tinjauan Persepsi Masyarakat Kota Banjarmasin) (Nasruddin, Syaharuddin, \& E. R. Normasari (eds.)). ULM Press.

Palimbunga, I. P. (2018). Keterlibatan Masyarakat Dalam Pengembangan Pariwisata Di Desa Wisata Tabalansu, Papua. Jurnal Master Pariwisata (JUMPA), 05, 193. https://doi.org/10.24843/jumpa.2018.v05.i01.p10

Priyanto, R., Syarifuddin, D., \& Sofa, M. (2018). Perancangan Model Wisata Edukasi di Objek Wisata Kampung Tulip. Jurnal Abdimas BSI: Jurnal Pengabdian Kepada Masyarakat, l(1), 32-38. https://ejournal.bsi.ac.id/ejurnal/index.php/abdimas/article/view/2863

Ridhoi, R., Anggraeni, R. M., Bahtiar, M., Ayundasari, L., \& Marsudi. (2020). The Development of Sendang Biru Beach in Malang Regency Through Marine Edutourism. 404(Icossei 2019), 165-171. https://doi.org/10.2991/assehr.k.200214.028

Suwantoro. (1997). Dasar-Dasar Pariwisata. Penerbit Andi.

Tisnawati, E., \& Ratriningsih, D. (2017). Pengembangan konsep pariwisata sungai berbasis masyarakat. Komposisi, 11(5), 189-201. https://ojs.uajy.ac.id/index.php/komposisi/article/view/1293

Yfantidou, G., \& Goulimaris, D. (2018). The exploitation of edutourism in educational society: A learning experience necessity through physical activity and recreation. Sport Science, 11(1), 8-15. 